\title{
Effects of School-based Smoking Prevention Education by Physician After Eight Years: A School Randomized Controlled Trial
}

\author{
Endo Masamitsu ${ }^{1, ~ *}$, Iwaki Norio ${ }^{2}$, Fukuda Tamutsu ${ }^{3}$, Yoshida Kenji ${ }^{3}$, Nomura Hideki ${ }^{4}$, \\ Kido Teruhiko ${ }^{5}$, Takahashi Yuko ${ }^{6}$, Ikeda Michiko ${ }^{7}$, Nakashima Motoko ${ }^{7}$, Morita Masato ${ }^{8}$, \\ Douniwa Kenichi', Kita Toshiyuki ${ }^{10}$ \\ ${ }^{1}$ Vascular Surgery, Jouhoku Hospital, Kanazawa, Japan \\ ${ }^{2}$ Iwaki Clinic of Internal Medicine, Kanazawa, Japan \\ ${ }^{3}$ Nonprofit Organization (NPO) Non-smoking Network Ishikawa, Kanazawa, Japan \\ ${ }^{4}$ General Medical Department, Kanazawa University Hospital, Kanazawa, Japan \\ ${ }^{5}$ Kanazawa University, Institute of Medical, Pharmaceutical, and Health Sciences, Kanazawa, Japan \\ ${ }^{6}$ Postgraduate School of Public Health, Faculty of Medicine, Kyoto University, Kyoto, Japan \\ ${ }^{7}$ Faculty of Health Sciences, Komatsu University, Komatsu, Japan \\ ${ }^{8}$ Morita Clinic, Kanazawa, Japan \\ ${ }^{9}$ Douniwa Clinic, Kanazawa, Japan \\ ${ }^{10}$ Respiratory Medicine, NHO Kanazawa Medical Center, Kanazawa, Japan
}

\section{Email address:}

m-endo@jouhoku.jp (E. Masamitsu), niwaki@wish.ocn.ne.jp (I. Norio), hakusan.prt.fkd@lapis.plala.or.jp (F. Tamutsu), kyoshida@spacelan.ne.jp (Y. Kenji),hnomhnom@gmail.com (N. Hideki), tkido@staff.kanazawa-u.ac.jp (K. Teruhiko), yukotak@mua.biglobe.ne.jp (T. Yuko), michiko.ikeda@komatsu-u.ac.jp (I. Michiko), motoko.nakashima@komatsu-u.ac.jp (N. Motoko), morita@kma.jp (M. Masato),doniwa@kma.jp (D. Kenichi), toshiyukikita7@yahoo.co.jp (K. Toshiyuki)

${ }^{*}$ Corresponding author

\section{To cite this article:}

Endo Masamitsu, Iwaki Norio, Fukuda Tamutsu, Yoshida Kenji, Nomura Hideki, Kido Teruhiko, Takahashi Yuko, Ikeda Michiko, Nakashima Motoko, Morita Masato, Douniwa Kenichi, Kita Toshiyuki. Effects of School-based Smoking Prevention Education by Physician After Eight Years: A School Randomized Controlled Trial. Journal of Health and Environmental Research. Vol. 6, No. 4, 2020, pp. 119-127. doi: $10.11648 /$ j.jher.20200604.13

Received: November 12, 2020; Accepted: November 30, 2020; Published: December 8, 2020

\begin{abstract}
Numerous studies have examined whether school-based smoking prevention education for minors reduces smoking rates, but consensus has not been established. Moreover, there are few reports about non-smoking classes offered by physicians with long-term results. Volunteer doctors have provided tobacco prevention classes in Kanazawa, Japan since 1998. The aim of this article is to assess whether the education by physicians was effective after eight years. A community area having 14 elementary schools was selected for this study. The study groups comprised randomized schools receiving the 45 minutes non-smoking education by physicians for 12-year-old sixth graders once a year and control schools with no intervention during three years from 2007 to 2009. A randomized controlled trial was conducted among 4,014 (1,615 educated and 2,399 control) students. After eight years, a questionnaire survey on the smoking behaviors of 20 -year-old young adults within the community was conducted and 1,634 (631 educated and 1,003 control) replies were collected. The smoking rates of the two groups were compared. At the eight-year follow-up, the smoking rates in the educated group significantly decreased compared to those in the control, especially among males. The school-based smoking prevention education by physicians was effective in reducing the smoking rates among 12 -year-old students 8 years later.
\end{abstract}

Keywords: Smoking, Prevention, Education, Physician, Long-term Results 


\section{Introduction}

The major factors that influence adolescent smoking initiation pertain to perceptions of smoking-related risks and misunderstood benefits of smoking [1]. Against this backdrop, the study considers that smoking prevention education (SPE) is essential and that it should be conducted in schools worldwide to discourage students from smoking. Numerous studies have been conducted in schools to determine the effectiveness of SPE for minors in reducing smoking rates. Although many studies have found the scheme to be effective [2-18], others have reported the opposite [19-25]; thus, a consensus about the results remains lacking [26, 27].

Why does a difference occur in the results of the effectiveness of SPE? Thomas et al. asserted that differences in educational methods may lead to diverse results in terms of effectiveness [27]. In fact, various approaches have been employed for SPE. Moreover, several authors reported that friends, family, and the social environment influenced the results of the program [26-32]. Identifying the factors that influence such differences is difficult because of the multiple elements in conjunction with the effect of the program. Despite the number of factors influencing smoking behavior, the present study aims to clarify the usefulness of SPE by physicians.

If the quantity or intensity of education is increased, then the effect of such education is expected to improve. A majority of authors suggested improving education through several sessions, whereas others recommended more than 10 classes $[2,4,5,7,8,11,12,19,23]$. Although the current study agrees with holding multiple classes, time is a constraining factor for the current work of research. Thus, only once-a-year education can be provided, and we were able to show the effectiveness. Then, the key question remains: What level of intensity is required to prove the effectiveness of SPE?

Class instructors play a crucial role in ensuring the success of in-school SPE. Teachers at schools are the most popular instructors, and they have a constant influence on students $[2-4,8,10,11,16]$. However, as smoking causes severe health problems, Kanazawa City Medical Association (KCMA) considered that physicians were the most appropriate professionals to offer non-smoking education. Nevertheless, only a handful of doctors and other health professionals have provided education in the literature $[5,9,14,27]$. In our opinion, we need to discuss the importance of doctors in SPE.

It is also important to consider how long the educational effectiveness in elementary schools lasts. As people can smoke legally in Japan once they reach the age of 20, we wanted to know the results in eight years. Nevertheless, we could find few reports with the results of over 5 years [2-4]. We would like to clarify the longer-term effectiveness of SPE by physicians.

Therefore, this study aimed to examine, over a period of eight years, the effectiveness of the 45-minute SPE once a year provided by doctors for 12-year-old students.

\section{Methods}

\subsection{Procedure}

KCMA established the Smoking Prevention Committee in 2005 and produced a PowerPoint-based program of SPE for elementary school students. The program contains information about the potential harm of smoking on the human body, especially on the lungs, heart, arteries, and brain, including passive smoking risks, and ways to counteract tobacco in society. It also covers the economic and social problems that result from tobacco-induced diseases, cigarette fire, and tobacco companies' propaganda. In addition, the program sets up the role-play game "how to refuse tobacco without being shy." KCMA has held SPE seminars for school doctors and/or local physicians to help them recognize the aim and skill of the SPE once a year since 2006. After the seminar, doctors visit elementary schools and provide SPE for 12-year-old students once a year.

\subsection{Subjects and Participants}

A community area that has 14 public elementary schools was selected for this study. KCMA proposed SPE to all schools and the agreement for SPE class by physician depended on each school. Doctors visited schools that had signed an agreement for 3 years from 2007 to 2009 . There was no intervention at the schools that had not signed the agreement.

After eight years, we carried out a questionnaire survey on the smoking behaviors of 20-year-old young adults who had attended the coming-of-age ceremony held at the community hall. The questionnaires were distributed to all the participants by the community hall staff members, who handed the questionnaires to the participants together with other coming-of-age ceremony-related documents at the venue's reception desk (Figure 1).

Participation was voluntary and the questionnaire was anonymous. It had three main question items: gender, graduated elementary school name, and current smoking patterns as follows.

1. Never smoked (never smoked even one puff of a cigarette and/or heated tobacco products).

2. Tried once (has smoked, but only once).

3. Quitter (has smoked more than once, but has quit for six months).

4. Regular (currently smokes at least once a week or more).

5. This study was approved by the Ethical Review Committee of Kanazawa Medical Center. 


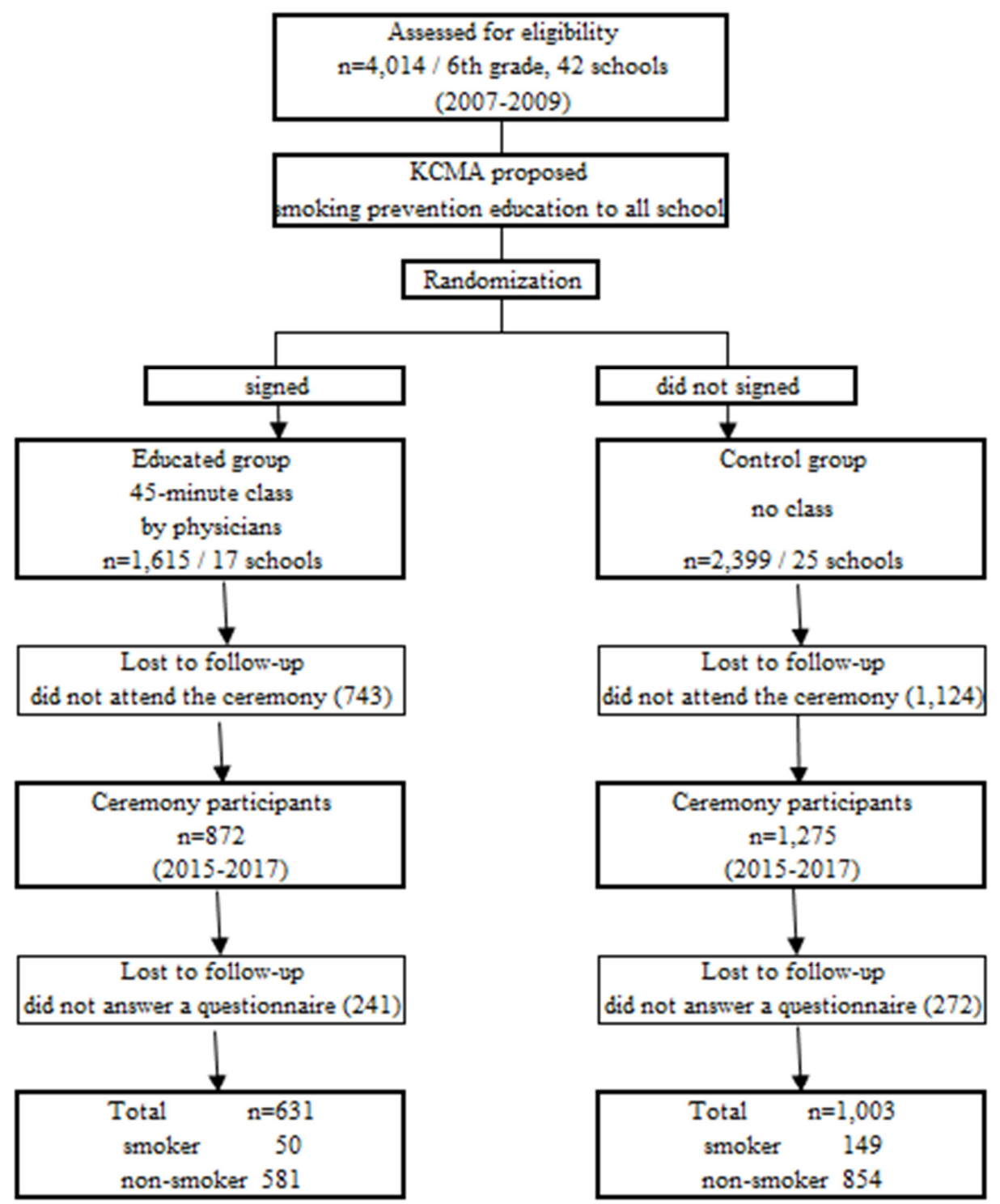

KCMA: Kanazawa City Medical Association

Figure 1. Study desighn and flow of Subjects.

\subsection{Data Analysis}

The ceremony participants who graduated from schools where doctors had provided SPE were defined as the "educated group" and those from schools where physicians did not provide the education were defined as the "control group". The participants who answered "Regular" were defined as "smokers" and others as "non-smokers". We compared the smoking behaviors of the total, males and females between the educated and control groups within a span of three years and in each year.

The results are presented as odds rations (OR), with 95\% confidence intervals and p-values. All analyses were performed using EZR version 1.41 software.

\section{Results}

The number of the educated schools and control schools was 3 and 11 in 2007, 6 and 8 in 2008, and 8 and 6 in 2009, respectively. The number of total subjects was $4,014(1,615$ educated and 2,399 control) during the three years. As the follow-up loss, 743 new-adults of the educated group and 1,123 ones of the control group did not attend the ceremony eight years later, so the number of participants in the coming-of-age ceremony was totaling to 2,147 (educated 872, control 1,275) for all the three years. In total, 241 of the educated group and 272 of the control group did not answer the survey; these were also the follow-up loss. Overall, 1,634 questionnaires were collected in free will over the three years (556 in 2015, 503 in 2016, and 575 in 2017) and the recovery rate was $40.7 \%$. The numbers of total smokers were 50 and 149 during the three years in the educated and control groups, respectively: 8 and 50 in 2015, 14 and 50 in 2016, and 28 and 49 in 2017 in the educated and control groups, respectively (Figure 1 and Table 1). 
Table 1. Number of elementary schools, subjects and recoveries after 8 years.

\begin{tabular}{|c|c|c|c|c|}
\hline \multirow{2}{*}{ Number of elementary school } & \multicolumn{4}{|c|}{ Intervention year } \\
\hline & 2007 & 2008 & 2009 & 3 years total \\
\hline Total & 14 & 14 & 14 & 42 \\
\hline Educated & 3 & 6 & 8 & 17 \\
\hline Control & 11 & 8 & 6 & 25 \\
\hline \multicolumn{5}{|l|}{ Number of subjects } \\
\hline Total & 1,379 & 1,280 & 1,355 & 4,014 \\
\hline Educated & 292 & 548 & 775 & 1,615 \\
\hline Control & 1,087 & 732 & 580 & 2,399 \\
\hline Questionnaire survey year & 2015 & 2016 & 2017 & 3 years total \\
\hline Number of recoveries & 556 & 503 & 575 & 1,634 \\
\hline Recovery rate $(\%)$ & 40.3 & 39.3 & 42.4 & 40.7 \\
\hline Educated, person (\%) & $156(28.1)$ & $207(41.1)$ & $268(46.6)$ & 631 \\
\hline Smoking $+/-$, male & $5 / 67$ & $10 / 93$ & $22 / 117$ & $37 / 277$ \\
\hline Female & $3 / 81$ & $4 / 100$ & $6 / 123$ & $13 / 304$ \\
\hline Total & $8 / 148$ & $14 / 193$ & $28 / 240$ & $50 / 581$ \\
\hline Control, person (\%) & $400(71.9)$ & $296(58.9)$ & $307(53.4)$ & 1,003 \\
\hline Smoking +/-, male & $40 / 152$ & $42 / 112$ & $34 / 147$ & $116 / 411$ \\
\hline Female & $10 / 198$ & $8 / 134$ & $15 / 111$ & $33 / 443$ \\
\hline Total & $50 / 350$ & $50 / 246$ & $49 / 258$ & $149 / 854$ \\
\hline
\end{tabular}

A significantly lower proportion of total smokers was observed in the educated groups compared to the control groups in all the three years-7.9\% vs. $14.9 \%$; OR $2.03,95 \%$ CI $1.45-$ $2.84, \mathrm{p}<0.001$-and in each year, $5.1 \%$ vs. $12.5 \%$; OR 2.64 , $95 \%$ CI $1.22-5.71, \mathrm{p}=0.011,6.7 \%$ vs. $16.9 \%$; OR $2.80,95 \% \mathrm{CI}$ $1.50-5.22, \mathrm{p}=0.001$ and $10.4 \%$ vs. $16.0 \%$, OR $1.63,95 \% \mathrm{CI}$ $1.00-2.68, p=0.046$ for 2015,2016 , and 2017 , respectively. The overall smoking rates of males were significantly lower in the educated groups when compared to the control groups in the three-year total-11.8\% vs. $22.0 \%$; OR $2.11,95 \%$ CI $1.42-3.15$, $\mathrm{p}<0.001$. The same results were also witnessed in 2015 and 2016 (6.9\% vs. 20.8\%; OR 3.53, 95\%CI 1.33-9.33, $\mathrm{p}=0.008$ and $9.7 \%$ vs. $27.3 \%$; OR $3.49,95 \%$ CI $1.66-7.33, \mathrm{p}=0.001$, respectively). However, in 2017, the smoking rate among males was not significantly lower in the educated groups compared to the control groups. The smoking rate of the female was not significant in the educated groups when compared to the control groups in 2015, 2016, and the three years total. However, in 2017 , the female smoking rate was significantly lower in the educated group compared to the control group (4.7\% vs. $11.9 \%$; OR 2.77, 95\%CI 1.04-7.39, $\mathrm{p}=0.035$ ).

The smoking rates were higher in male when compared to female in both groups: $6.9 \%$ vs. $3.6 \%, 9.7 \%$ vs. $3.8 \%$, and $15.8 \%$ vs. $4.7 \%$ in the educated group in 2015,2016 , and 2017 , respectively. The smoking rates of the control group in male when compared to female were $20.8 \%$ vs. $4.8 \%, 27.3 \%$ vs. $5.6 \%$, and $18.8 \%$ vs. $11.9 \%$ in 2015,2016 , and 2017 , respectively (Table 2 ).

Table 2. Odds ratios, 95\%cofidence intervals for smoking rates between educated and control groups.

\begin{tabular}{|c|c|c|c|c|c|}
\hline Characteristics & Total & Smokers/Total n/N (\%) & OR & $95 \% \mathrm{CI}$ & p-value \\
\hline \multicolumn{6}{|c|}{ All participants all years } \\
\hline Educated & 631 & $50 / 631(7.9)$ & 2.03 & $1.45-2.84$ & $<0.001$ \\
\hline Control & 1003 & $149 / 1003(14.9)$ & ref & & \\
\hline \multicolumn{6}{|c|}{ All participants 2015} \\
\hline Educated & 156 & $8 / 156(5.1)$ & 2.64 & $1.22-5.71$ & 0.011 \\
\hline Control & 400 & $50 / 400(12.5)$ & ref & & \\
\hline \multicolumn{6}{|c|}{ All participants 2016} \\
\hline Educated & 207 & $14 / 207(6.7)$ & 2.8 & $1.50-5.22$ & 0.001 \\
\hline Control & 296 & $50 / 296(16.9)$ & ref & & \\
\hline \multicolumn{6}{|c|}{ All participants 2017} \\
\hline Educated & 268 & 28/268 (10.4) & 1.63 & $1.00-2.68$ & 0.046 \\
\hline Control & 307 & 49/307 (16.0) & ref & & \\
\hline \multicolumn{6}{|c|}{ Male gender all years } \\
\hline Educated & 314 & $37 / 314(11.8)$ & 2.11 & $1.42-3.15$ & $<0.001$ \\
\hline Control & 527 & $116 / 527(22.0)$ & ref & & \\
\hline \multicolumn{6}{|l|}{ Male gender 2015} \\
\hline Educated & 72 & $5 / 72(6.9)$ & 3.53 & $1.33-9.33$ & 0.008 \\
\hline Control & 192 & 40/192 (20.8) & ref & & \\
\hline \multicolumn{6}{|l|}{ Male gender 2016} \\
\hline Educated & 103 & 10/103 (9.7) & 3.49 & $1.66-7.33$ & 0.001 \\
\hline Control & 154 & $42 / 154(27.3)$ & ref & & \\
\hline \multicolumn{6}{|l|}{ Male gender 2017} \\
\hline Educated & 139 & 22/139 (15.8) & 1.23 & $0.68-2.22$ & 0.49 \\
\hline Control & 181 & 34/181 (18.8) & ref & & \\
\hline
\end{tabular}




\begin{tabular}{|c|c|c|c|c|c|}
\hline Characteristics & Total & Smokers/Total n/N (\%) & OR & $95 \% \mathrm{CI}$ & p-value \\
\hline \multicolumn{6}{|c|}{ Female gender all years } \\
\hline Educated & 317 & $13 / 317(4.1)$ & 1.74 & $0.90-3.36$ & 0.095 \\
\hline Control & 476 & $33 / 476(6.9)$ & ref & & \\
\hline \multicolumn{6}{|c|}{ Female gender 2015} \\
\hline Educated & 84 & 3/84 (3.6) & 1.36 & $0.37-5.08$ & 0.643 \\
\hline Control & 208 & $10 / 208(4.8)$ & ref & & \\
\hline \multicolumn{6}{|c|}{ Female gender 2016} \\
\hline Educated & 104 & 4/104 (3.8) & 1.49 & $0.44-5.10$ & 0.52 \\
\hline Control & 142 & $8 / 142(5.6)$ & ref & & \\
\hline \multicolumn{6}{|c|}{ Female gender 2017} \\
\hline Educated & 129 & 6/129 (4.7) & 2.77 & $1.04-7.39$ & 0.035 \\
\hline Control & 126 & $15 / 126(11.9)$ & ref & & \\
\hline
\end{tabular}

\section{Discussion}

The study found that an SPE session lasting $45 \mathrm{~min}$ provided once a year by related doctors for sixth graders significantly reduced smoking rate after eight years, especially among males. However, initially, the study expected the opposite of significant smoking rate reduction because the method employed has very low frequency, that is, once a year. In contrast, a majority of previous studies reported multiple interventions within one to several years $[2,3,5,7,8,11,12$, $19,23]$. Bast et al. employed a program that consisted of eight teaching lessons per year with parental involvement and smoke-free school grounds [12]. Shean et al. provided five classes a year, whereas Crone et al. proposed a program with three classes per year for 2 years [3, 8]. Moreover, Hanewinkel et al. tested the life-skills approach to smoking prevention in Austria, Denmark, Luxembourg, and Germany with a program lasting for 21 sessions. However, their results pointed to a weak effect on lifetime smoking prevalence and experimental smoking [19]. Flay et al. introduced a scheme wherein students underwent a social influence curriculum in six core and two maintenance sessions in sixth grade, two booster sessions in seventh grade, and one booster session in eighth grade for 11 sessions [2].

The present study is in agreement with the aforementioned authors with respect to increased educational effectiveness relative to the frequency of teaching sessions. However, the frequency of the sessions for the current study is limited to only once a year because of constraints in time and finances for KCMA and the schools. Conversely, Lisbo et al. reported the effectiveness of $90 \mathrm{~min}$ of SPE in a classroom setting provided by medical students 1 year later [13]. Moreover, Stamm-Balderjahn et al. suggested that only one 2-hour session held by doctors was beneficial despite the fact that the session was carried out in a hospital rather than in a school [9]. Based on the aforementioned studies, the current study proposed that education by medical students or doctors leaves a deep and strong impression on pupils.

Teachers implement the non-smoking contents of the curriculum $[2-4,8,11,19,22,23,27]$, as shown in Table 3, which has a constant effect $[2-4,8,10,11,16]$.

Table 3. Results and characteristics of short and long-term follow-up studies on smoking prevention education.

\begin{tabular}{|c|c|c|c|c|c|c|c|c|}
\hline \multirow{2}{*}{ Author } & \multirow{2}{*}{ Instructor } & \multicolumn{2}{|c|}{ Participants } & \multirow{2}{*}{ Age } & \multirow{2}{*}{$\begin{array}{l}\text { Curriculum } \\
\text { Intensity }\end{array}$} & \multirow{2}{*}{ Interval } & \multirow{2}{*}{ Effective } & \multirow{2}{*}{ Nation } \\
\hline & & Baseline & Recovery, n or \% & & & & & \\
\hline \multicolumn{9}{|l|}{ Short-term follow-up } \\
\hline $\begin{array}{l}\text { Stamm-Balderjahn et al., } \\
2016\end{array}$ & $\begin{array}{l}\text { physicians } \\
\text { (at hospital) }\end{array}$ & 760 & 625 & $12-19$ & $2 \mathrm{hr} \times 1$ & $6 \mathrm{mo}$ & yes & Germany \\
\hline Malcon et al., 2011 & teachers & 2,209 & 2,066 & 13,14 & $\begin{array}{l}9 \mathrm{hr} \\
\text { divided into } 2 \text { times }\end{array}$ & $6 \mathrm{mo}$ & $\begin{array}{l}\text { no } \\
\text { (+urine } \\
\text { test) }\end{array}$ & Brazil \\
\hline Crone et al., 2011 & teachers & 3,173 & $57 \%$ & $11-12$ & $3 / y r \times 2$ & $1 \mathrm{yr}$ & yes & Netherland \\
\hline Lisboa et al., 2020 & $\begin{array}{l}\text { medical } \\
\text { student }\end{array}$ & 2,348 & $57.60 \%$ & $12-21$ & $90 \mathrm{~min}$, once & $1 \mathrm{yr}$ & yes & Brazil \\
\hline Hanewinkel et al., 2004 & teachers & 1,858 & $87.50 \%$ & 11.4 & $21 / 4 \mathrm{mo}$ & $15 \mathrm{mo}$ & no & $\begin{array}{l}\text { Austria } \\
\text { Denmark } \\
\text { Luxembourg } \\
\text { Germany }\end{array}$ \\
\hline Bast et al., 2019 & $\begin{array}{l}\text { teachers \& } \\
\text { parents }\end{array}$ & 4,161 & $\begin{array}{l}8 \mathrm{mo} ; 3,764 \\
18 \mathrm{mo} ; 3,269\end{array}$ & 12.5 & $8 / \mathrm{yr}$ & $\begin{array}{l}6 \mathrm{mo} \\
18 \mathrm{mo}\end{array}$ & $\begin{array}{l}\text { yes } \\
\text { yes }\end{array}$ & Denmark \\
\hline \multirow[t]{2}{*}{ Wen et al., 2010} & teachers & 2,343 & 1yr; 1926 & 13,14 & $\begin{array}{l}\text { multi-level } \\
\text { intervention }\end{array}$ & $1 \mathrm{yr}$ & yes & China \\
\hline & & & $2 \mathrm{yr} ; 859$ & & & $2 \mathrm{yr}$ & no & \\
\hline Hort et al., 1995 & $\begin{array}{l}\text { physicians } \\
\& \text { teacher }\end{array}$ & 878 & 630 & 13 & $1-2 h \times 4+1 h \times 15$ & $2 \mathrm{yr}$ & yes & Germany \\
\hline McMenamin et al., 2018 & teachers & 47,981 & $44.30 \%$ & $\begin{array}{l}12,15 \\
18\end{array}$ & TUPE & NS & yes & USA \\
\hline \multicolumn{9}{|c|}{ Long-term (more than six years) } \\
\hline Flay et al., 1989 & teachers & 691 & $90 \%$ & $12-14$ & 8 in 6 grade + & $6 \mathrm{yr}$ & yes & Canada \\
\hline
\end{tabular}




\begin{tabular}{|c|c|c|c|c|c|c|c|c|}
\hline \multirow{2}{*}{ Author } & \multirow{2}{*}{ Instructor } & \multicolumn{2}{|c|}{ Participants } & \multirow{2}{*}{ Age } & \multirow{2}{*}{$\begin{array}{l}\text { Curriculum } \\
\text { Intensity }\end{array}$} & \multirow{2}{*}{ Interval } & \multirow{2}{*}{ Effective } & \multirow{2}{*}{ Nation } \\
\hline & & Baseline & Recovery, n or \% & & & & & \\
\hline & & & & & $\begin{array}{l}2 \text { in grade } 7+ \\
1 \text { in grade } 8\end{array}$ & & & \\
\hline Botvin et al., 1995 & teachers & 3,597 & $60 \%$ & 13 & $\begin{array}{l}15 \text { in grade } 7+ \\
10 \text { in grade } 8+ \\
5 \text { in grade } 9 \\
\text { include drug, life skill }\end{array}$ & $6 \mathrm{yr}$ & yes & USA \\
\hline Shean et al., 1994 & $\begin{array}{l}\text { teachers } \\
\text { and peers }\end{array}$ & 2,366 & $37.1 \%$ & 7 & $5 / \mathrm{yr}$ & $7 \mathrm{yr}$ & $\begin{array}{l}\text { girl; yes } \\
\text { boy; no }\end{array}$ & Australia \\
\hline Current paper, 2020 & physicians & 4,013 & $163440.7 \%$ & 12 & 1 & $8 \mathrm{yr}$ & $\begin{array}{l}\text { total; yes } \\
\text { boy; yes } \\
\text { girl; no }\end{array}$ & Japan \\
\hline
\end{tabular}

TUPE; The California Tobacco-use Prevention Education program, NS; not state.

However, KCMA initially thought that medical personnel, such as pharmacists, nurses, medical students, and doctors, are more suitable lecturers than the education staff because cigarettes directly harm the body and health. Some papers reported the effectiveness of a school-based anti-smoking intervention by pharmacists, nurses, health professionals, and medical students $[13,14,33,34]$. Moreover, Hort et al. pointed out that SPE was effective when teachers and doctors jointly taught the adverse effects of smoking [5]. According to Epps et al., five sessions by physicians per year for at least two years are necessary for sustained results [28]. Furthermore, as I mentioned before Stamm-Balderjahn et al. indicate that doctors' lectures once for two hours for students who visit their hospitals are effective [9]. All these studies suggest that anti-smoking education by medical personnel, especially physicians, is very useful. As a conclusion of the lecturer within these medical personnel, KCMA decided that physicians were the most appropriate professionals and have provided the classes since 1998 .

Nevertheless, recent studies indicate that physicians substantially undertreat tobacco addiction compared with other chronic conditions, such as diabetes or hypertension [35, 36]. Epps et al. emphasized that the elimination of tobacco use requires a comprehensive strategy, including health professional intervention, and that physicians and health professionals have major roles to play [28]. Physicians usually take care of sick people, but they also have a social responsibility to promote school-based tobacco prevention programs to students. Therefore, we believe that involving local doctors in SPE can help achieve the maximum educational effect in the shortest time and lowest cost.

The study assumes that the pupils' memory of SPE may fade over time. Thus, evaluating the effectiveness of SPE over time, eight years for this study, in particular, is important. There are many articles that have shown less than 2-3 years' results $[5,8-15,19,22,23,27]$. On the contrary, we think the goal of SPE is to ensure that students do not engage in smoking by the time they turn 20 , which is the legally accepted age for smoking in Japan. Dobbins et al. also thought that the true measure of success is the absence of smoking in the long term (age 18) and emphasized the lack of evidence for long-term effectiveness. Hence, they assumed it necessary to lengthen the evaluation periods to age 18. To our knowledge, as shown in Table 3, we could find only three reports that have covered more than six years [2-4]. Two reports indicated education was effective after six years $[2,4]$. Shean et al. showed the effectiveness after seven years in girls, but it did not show that of boys [3]. The lecturers in all these three papers were teachers. In this report, we were able to show the post-eight-years effectiveness of the SPE class by physicians.

When it comes to gender-related effect, our study noted significant differences among males but not among females. On the contrary, three European researchers reported that school-based SPE was more effective in females when compared with males $[3,5,9]$. Although it is difficult to clarify the reason, the WHO indicates that the young adult smoking rate in Europe is higher than in any other area and that of females is nearly $20 \%$ [37]. Hort et al. investigated the smoking rate of 13 -year-old female students, which increased from $20.3 \%$ to $41.2 \%$ in the intervention group and from $15 \%$ to $59.3 \%$ in the control group after 2 years [5]. In addition, Stamm-Balderjahn et al. found that the baseline smoking rate for females was $40.5 \%$ in the control group and $42.7 \%$ in the intervention group, although the mean age was 16 years and the study included water pipe [9]. Otherwise, the female smoking rate in Japan is $10 \%$ or lower, and it has hardly changed in the past 20 years [38]. In addition, the results of this study revealed that the three-year average smoking rate for women was $4.1 \%$ in the educated group and $6.9 \%$ in the control group. Since the smoking rate among Japanese females is very low, it is presumed that no difference was seen between the educated and the control groups in females.

Moreover, gender differences were examined in terms of smoking rate in 2017. The results illustrated that the rate among males was non-significantly lower in the intervention group when compared with the rate among those in the control group. In contrast, this rate was significantly lower for women (OR 2.77; 95\% CI 1.04-7.39; p value $=0.035$ ) in the intervention group compared with control. The result is contradictory to that obtained across 3 years. Although pinpointing the cause is difficult, the study suggests that many factors, such as friends, siblings, parents, social norms, and cigarette advertisements, other than education may contribute to the increased rate. [26, 27, 29-32], Furthermore, opportunities to obtain a non-smoking education setting after graduating from elementary school differ from one person to another. As the next step, the current study proposes a detailed 
examination of these factors, except for school education.

\section{Limitations}

Population movement is one of the limitations of this study. As some students had moved away during the eight-year span, the individuals who participated in the coming-of-age ceremony were not exactly the same ones. However, both group recoveries were clearly defined with the graduated elementary schools. There might have been a school change problem with regard to population movement. Nevertheless, most SPE classes were held between June and October, and the sixth graders graduated the following March, so none or very few students may have changed school during the short time between prevention classes and graduation. Moreover, there were no or possibly very few other schools in which doctors provided SPE at that time. Therefore, we think that population movement barely affected smoking rates.

As we did not uniformly investigate the smoking rate of the subjects as a baseline in the whole schools, we are not able to deny the possibility that missing the baseline data in this study becomes one of the limitations. Most reports investigate it including baseline $[3,5,9,12,22]$ and data of around 12 years old was from 10 to $30 \%[3,5,12,13]$. In contrast, as a study in Japan into smoking rate of the sixth grader, Kawabata et al. reported that it was 1\% with the man and woman in 1991 [29]. However, it was considerably a report of the past. Therefore, we took the report of 2008 of the Ministry of Health and Welfare in Japan into account, besides the investigation was for seventh graders, one year older than sixth [38]. According to this report, it was $1.3 \%$ of schoolboys and $1.0 \%$ of schoolgirls that had the smoking experience more than once a month. As Kawabata et al. explained, it is fortunately thou:ht that there are extremely few smokers around sixth graders in Japan. Thus, it was expected that the baseline smoking rate of our study was extremely low. Then, it was thought that the baseline rates of both groups were not so different and the influence to give for the result of this study was small.

The authors carrying out a short-term follow-up, up to 2 years, obtained information within schools $[5,8,9,10,12-13$, 19, 22, 23]. Moreover, Flay et al. obtained information from high schools in 1989, which is approximately 6 years after the study was conducted [2]. However, collecting follow-up data from schools in terms of longitudinal investigation is difficult. Shean et al. collected the longest data after seven years by mail [3]. Moreover, Botvin collected data via telephone and mail 6 years after the study [4]. In the current study, follow-up applied to young adults. Thus, data were collected at official events such as coming-of-age ceremonies. Although this method is unique and innovative, it may represent a limitation and/or bias because participants to the ceremony may be considered "good" people who, in general, fit societal expectations and thus voluntarily participated in the local event. Moreover, the possibility exists that the non-smoking ratio of "good" people was high. Thus, bias can lead to beneficial effects of the SPE. However, the authors considered that many attendees replying to the letter or telephone call and participating in the ceremony are the so-called "good" people. In addition, the possibility that the factors of the long-term investigation may influence smoking rate is undeniable. In contrast, however, omitting such factors may also lead to difficulty in determining the extent of influence of SPE.

\section{Conclusion}

SPE class for 45 minutes once a year provided by physicians for sixth graders significantly reduced the smoking rate after eight years, especially among males.

\section{Acknowledgements}

This result was announced at the 34th Japanese Association of Smoking Control Science meeting held in Nagoya on October 28, 2018, and the Global Tobacco Free Summit, Tobacco Induced Diseases 15th Annual Conference on October 13, 2019, held in Tokyo.

The authors would like to thank Enago (www.enago.jp) for English language review.

\section{References}

[1] Anna Song, Holly ER Morrell, Jodi Cornell, Malena Ramos, Michael Biehl, Rhonda Kropp et al. Perceptions of smoking-related risks and benefits as predictors of adolescent smoking initiation. Am J Public Health. 2009; 99 (3): 487-4992. https://doi.org/10.2105/AJPH.2008.137679.

[2] Brian Flay, David Koepke, Shirley Thomson, Susanne Santi, Allan Best, Stephen Brown. Six-year follow-up of the first Waterloo school smoking prevention trial. Am J Public Health. 1989; $\quad 79 \quad$ (10): 1371-1376. https://doi.org/10.2105/AJPH.79.10.1371.

[3] Ruth Shean, Nicholas de Klerk, Bruce Armstrong, Noni Walker. Seven-year follow-up of a smoking-prevention program for children. Aust Nz J Publ Heal. 1994; 18 (2): 205-208. https://doi.org/10.1111/j.1753-6405.1994.tb00227.x.

[4] Gilbert Botvin, Eli Baker, Linda Dusenbury, Elizabeth Botvin, Tracy Diaz. Long-term follow-up results of a randomized drug abuse prevention trial in a white middle-class population.

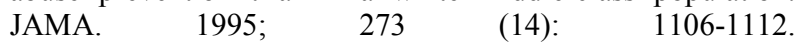
https://doi.org/10.1001/jama.1995.03520380042033.

[5] W Hort, H Hort, R Willers. An interventional study against cigarette smoking among Dusseldorf high school students 1992-94. Clin Res Cardiol. 1995; 84 (9): 700-11.

[6] Brian Flay. Effectiveness of school-based smoking prevention programs. World Health Organization Tobacco Free Initiative 2008; $1-58$.

[7] Brian Flay. School-based smoking prevention programs with the promise of long-term effects. Tob Induc Dis. 2009; 5 (1): 1-18. https://doi.org/10.1186/1617-9625-5-6.

[8] Crone MR, Spruijt R, Dijkstra NS, Willemsen MC, Paulussen TGWM. Does a smoking prevention program in elementary schools prepare children for secondary school? Prev Med. 2011; 52 (1): 53-59. https://doi.org/10.1016/j.ypmed.2010.11.003. 
[9] Sabine Stamm-Balderjahn, David Groneberg, Bianca Kusma, Anita Jagota, Nicolas Schönfeld. Smoking prevention in school students, positive effects of a hospital-based intervention. Deutsches Ärzteblatt. 2012; 109 (44): 746-752. https://doi.org/10.3238/arztebl.2012.0746.

[10] Sara McMenamin, Sharon Cummins, Yue-Lin Zhuang, Anthony Gamst, Carlos Ruiz, Antonio Mayoral et al. Evaluation of the tobacco-use prevention education (TUPE) program in California. PLOS ONE. 2018; 13 (1): e0206921. https://doi.org/10.1371/journal.pone.0206921.

[11] Lotus Bast, Pernille Due, Pernille Bendtsen, Lene Ringgard, Louise Wohllebe, Mogens Trab Damsgaard et al. High impact of implementation on school-based smoking prevention: The X: IT study-a cluster randomized smoking prevention trial. Implement Sci. 2016; 11 (1): 1-14. https://doi.org/10.1186/s13012-016-0490-7.

[12] Lotus Bast, Anette Andersen, Annette Kjær Ersbøll, Pernille Due. Implementation fidelity and adolescent smoking: The $\mathrm{X}$ : IT study-A school randomized smoking prevention trial. Eval Program Plann. 2019; 72: 24-32. https://doi.org/10.1016/j.evalprogplan.2018.09.004.

[13] Oscar Lisboa, Breno Bernardes-Souza, Luiz Xavier, Matheus Almeida, Paulo Corrêa, Titus Brinker. A smoking prevention program delivered by medical students to secondary schools in Brazil called "Education AGAINST Tobacco": randomized controlled trial. J Med Internet Res. 2019; 21 (2): e12854. https://doi.org/10.2196/12854.

[14] Maureen Dobbins, Kara DeCorby, Steve Manske, Elena Goldblatt. Effective practices for school-based tobacco use prevention. Prev Med. 2008; 46 (4): 289-297. https://doi.org/10.1016/j.ypmed.2007.10.003.

[15] Steve Sussman, Bridget Arriaza, Timothy J. Grigsby. Alcohol, tobacco, and other drug misuse prevention and cessation programming for alternative high school youth: A review J Sch $\begin{array}{lllll}\text { Health. } & 2014 ; & 84 & \text { (11): } & 748-58\end{array}$ https://doi.org/10.1111/josh.12200.

[16] Gilbert J. Botvin, Kenneth W. Griffin, Christopher Williams, Preventing daily substance use among high school students using a cognitive-behavioral competence enhancement approach. World Journal of Preventive Medicine. 2015; 3 (3): 48-53. doi: 10.12691/jpm-3-3-1.

[17] Georgie J. MacArthur, Sean Harrison, Deborah M. Caldwell, Matthew Hickman, Rona Campbell. Peer-led interventions to prevent tobacco, alcohol and/or drug use among young people aged 11-21 years: a systematic review and meta-analysis. Addiction 2016; 111: 391-407. doi: 10.1111/add.13224.

[18] Allen Thurston, Laura Dunne, Frank Kee, Aidean Gildea, Nicole Craig, Patrick Stark, Anne Lazenbatt. A randomized controlled efficacy trial of a smoking prevention programme with Grade 8 students in high schools. Int J Educ Res 2019; 93:, 23-32. https://doi.org/10.1016/j.ijer.2018.10.003.

[19] Reiner Hanewinkel, Martin Aßhauer. Fifteen-month follow-up results of a school-based life-skills approach to smoking prevention. Health Educ Res. 2004; 19 (2): 125-137. https://doi.org/10.1093/her/cyg018.

[20] Sarah Wiehe, Michelle Garrison, Dimitri Christakis, Beth Ebel, Frederick Rivara. A systematic review of school-based prevention trials with long-term follow-up. J Adolesc Health. 2005; 36 (3): 162-169. https://doi.org/10.1016/j.jadohealth.2004.12.003.
[21] Eunok Park. School-based smoking prevention programs for adolescents in South Korea: A systematic review. Health Educ Res. 2006; 21 (3): 407-415. https://doi.org/10.1093/her/cyl038.

[22] Maura Malcon, Ana Menezes, Maria Assunção, Marilda B Neutzling, Pedro Challal. Effectiveness of an educational intervention on smoking among school adolescents. Rev Bras Epidemiol. 2011; 14: 63-72.

[23] Xiaozhong Wen, Weiqing Chen, Kim Gans, Suzanne Colby, Ciyong Lu, Caihua Liang et al. Two-year effects of a school-based prevention programme on adolescent cigarette smoking in Guangzhou, China: A cluster randomized trial. Int J $\begin{array}{lllll}\text { Epidemiol. } & 2010 ; & 39 & \text { (3): } & \text { 860-876. }\end{array}$ https://doi.org/10.1093/ije/dyq001.

[24] Veldwijk J, Hoving C, van Gelder BM, Feenstra TL. Potential reach of effective smoking prevention programmes in vocational schools: Determinants of school directors' intention to adopt these programmes. J Public Health. 2012; 126 (14): 338-342. https://doi.org/10.1016/j.puhe.2012.01.002.

[25] Rebecca Kate Hodder, Megan Freund, Luke Wolfenden, Jenny Bowman, Smriti Nepal, Julia Dray, Melanie Kingsland, Sze Lin Yoong, John Wiggers. Systematic review of universal school-based 'resilience' interventions targeting adolescent tobacco, alcohol or illicit substance use: a meta-analysis. Prev $\begin{array}{llll}\text { Med. } & \text { 2017; } & \text { 100: } & \text { 248-268 }\end{array}$ https://doi.org/10.1016/j.ypmed.2017.04.003.

[26] Rafael Perera, Julie McLellan, Roger Thomas. School-based programmes for preventing smoking. Cochrane database of $\begin{array}{llll}\text { systematic } \quad \text { reviews } 2013 ; & 30 \text { : }\end{array}$ https://doi.org/10.1002/ebch.1937.

[27] Roger Thomas, Julie McLellan, Rafael Perera. Effectiveness of school-based smoking prevention curricula: Systematic review and meta-analysis. BMJ Open. 2015; 5 (3): 1-15. http://dx.doi.org/10.1136/bmjopen-2014-006976.

[28] Roselyn Epps, Marc Manley, Thomas Glynn.. Tobacco use among adolescents. Strategies for prevention. Pediatr Clin North Am. 1995; $42 \quad$ (2): $389-402$. https://doi.org/10.1016/S0031-3955 (16)38953-2.

[29] Tetsuro Kawabata. Smoking prevention education for adolescents in Japan. Jpn Med Assoc J. 2002; 45 (8): 324-328.

[30] Backinger CL, Fagan P, Matthews E, Grana R. Adolescent and young adult tobacco prevention and cessation: Current status and future directions. Tob Control. 2003; 12: 46-53. http://dx.doi.org/10.1136/tc.12.suppl_4.iv46.

[31] Backhaus I, D'Egidio V, Grassucci D, Gelardini M, Ardizzone C, La Torre G. Link between perceived smoking behaviour at school and students smoking status: A large survey among Italian adolescents. J Public Health. 2017; 151: 169-176. https://doi.org/10.1016/j.puhe.2017.07.004.

[32] Christine M. Steeger, Marina Epstein, Karl G. Hill, Allison N. Kristman-Valente, Jennifer A. Bailey, Jungeun Olivia Lee, Rick Kosterman. Time-varying effects of family smoking and family management on adolescent daily smoking: The moderating roles of behavioral disinhibition and anxiety. Drug Alcohol Depend. 2019; 204 (1): 1-7, 107572. https://doi:.org/10.1016/j.drugalcdep.2019.107572.

[33] Man-Tzu Wu, Wan-Chen Shen, Juei-Chia Chang, Yi-Chun Chiang, Hsiang-Mei Chen, Hsiang-Yin Chen. The impact of a pharmacist-conducted interactive anti-smoking education program on the attitudes and knowledge of high school students. 


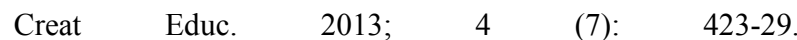
http://dx.doi.org/10.4236/ce.2013.4706.

[34] Lori Pbert, Susan Druker, Joseph DiFranza, Diane Gorak, George Reed, Robert Magner et al. Effectiveness of a school nurse-delivered smoking intervention for adolescents. $\begin{array}{llll}\text { Pediatrics. } & \text { 2011; } & 128 & \text { (5): } \quad 926-936 .\end{array}$ https://doi.org/10.1542/peds.2011-0520.

[35] Bernstein S, Yu S, Post L, Dziura J, Rigotti NA. Undertreatment of tobacco use relative to other chronic conditions. Am J Public Health. 2013; 103: e59-e65. https://doi.org/10.2105/AJPH.2012.301112.

[36] Tobias Raupach, Jan Falk, Eleni Vangeli, Sarah Schiekirka,
Christa Rustler, Maria Caterina Grassi et al. Structured smoking cessation training for health professionals on cardiology wards: A prospective study. Eur J Prev Cardiol. 2014; $21 \quad$ (7): 915-922. https://doi.org/10.1177/2047487312462803.

[37] World Health Organization. Data and Statistics. http://www.euro.who.int/en/health-topics/disease-prevention/t obacco/data-and-statistics Accessed January15, 2020.

[38] Japan Health Promotion \& Fitness Foundation. http://www.health-net.or.jp/tobacco/product/pd100000.html. Published January 15, 2020. Accessed January 15, 2020. 